\title{
Yarıiletken Aygıt Karakterizasyonu için Arduino UNO Tabanlı Otomatik Hall/Direnç Ölçüm Sistem Tasarımı ve Uygulaması
}

\section{Arduino UNO Based Automated Hall/Resistance Measurement System Design and Application for Semiconductor Device Characterization}

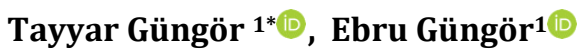 \\ ${ }^{1}$ Burdur Mehmet Akif Ersoy Üniversitesi Mühendislik-Mimarlık Fakültesi Enerji Sistemleri Mühendisliği Bölümü, \\ Burdur, TÜRKIYE \\ Sorumlu Yazar / Corresponding Author*: tgungor@mehmetakif.edu.tr \\ Geliș Tarihi / Received: 01.06.2021 Araștirma Makalesi/Research Article \\ Kabul Tarihi / Accepted: 15.09.2021 DOI:10.21205/deufmd.2022247019 \\ Atıf șekli/How to cite: GÜNGÖR,T.,GÜNGÖR, E.(2022). Yariletken Aygıt Karakterizasyonu için Arduino UNO Tabanlı Otomatik Hall/Direnç \\ Ölçüm Sistem Tasarımı ve Uygulaması.DEUFMD, 24(70), 205-212.
}

\section{$\ddot{0} \mathbf{z}$}

Bu çalışmada, yarıiletkenlerin aygıt karakterizasyonu için ortam koşullarına bağlı değişimlerde olası kullanıcı hatalarını, maliyet ve zahmeti azaltmak amacıyla Arduino UNO ile kontrol edilen otomatik Hall/Direnç (OHD) ölçüm sistem tasarımı yapılarak, çeşitli yarıiletken örnekler üzerinde kullanımı test edilmiștir. Geliștirilen bu sistemde yariletken örnek yüzeyinde olușturulan Van der Pauw konfigürasyonundaki elektriksel kontaklar, on iki adet tek-kontak rölenin uygun olan çlkışlarına 8bitlik kontrol sinyali ile yönlendirilmiştir. Bu işlem, uygun kontrol sinyalleri ile test edilen devre elemanının (DUT) belirli terminallerinden akım uygulanmasını ve bu akımın neden olduğu gerilim farkının ilgili kontaklar arasından ölçülmesini sağlamaktadır. Deneysel verilerin toplanması, istatiksel analiz ve gerekli diğer hesaplamalar ardışık olarak aynı bilgisayar programı içinde yapılabilmektedir. Dolayısıyla sistematik, hızlı ve güvenilir bir karakterizasyon yapılması mümkün hale gelmektedir. Tararlanan bu sistem ile seri şekilde yüzey direnci, özdirenç ile manyetik alan etkisindeki taşıyıcı konsantrasyonu, taşıyıcı türü, mobilite değerleri belirlenebilmektedir. Sistemin uygulamadaki performansı referans örnekler için test edildiğinde, elde edilen ölçüm sonuçları arasında oldukça iyi bir uyum olduğu gözlenmiştir. Diğer taraftan yeni tasarım ölçüm sistemi ile daha düşük maliyetli ve taşınabilir bir yapı oluşturulabilmiştir. Bu tasarlanan yeni OHD ölçüm sistemi yarıiletkenlerin sıcaklık, ışık şiddeti ve dalgaboyuna bağlı olarak karakterize edilmesi için de oldukça elverişli özelliklere sahiptir.

Anahtar Kelimeler: Hall mobilitesi, Taşıyıcı konsantrasyonu, Van der Pauw tekniği, Yüzey direnci,, Arduino UNO.

\begin{abstract}
In this study, to reduce potential user errors, cost, and effort due to changes in environmental conditions for device characterization of semiconductors an automatic Hall/Resistance (AHD) measurement system was designed with Arduino UNO and the system was tested on various semiconductor samples. In this developed system, electrical contacts in Van der Pauw configuration formed on the semiconductor sample surface directed to the appropriate outputs of twelve single-
\end{abstract}


contact relays with an 8-bit control signal. This process ensures that current applied from certain terminals of the tested circuit element (DUT) with appropriate control signals and the voltage difference caused by this current measured between the relevant contacts. Collection of experimental data, statistical analysis, and other necessary calculations can be done sequentially in the same computer program. Therefore, a systematic, fast and reliable characterization becomes possible. With this designed system, surface resistance, resistivity, and carrier concentration under the influence of the magnetic field, carrier type, and mobility values can be determined in series. When the application performance of the system was tested for reference samples, it was observed that there was a very good agreement between the measurement results obtained. On the other hand, a lower cost and portable structure created with the new design measurement system. This new designed AHD measuring system also has very convenient properties for characterizing semiconductors based on temperature, light intensity, and wavelength.

Keywords: Hall mobility, Carrier concentration, Van der pauw technique, Sheet resistance, Arduino UNO.

\section{Giriş}

Yariletken malzemeler, farklı teknikler kullanılarak uygun alttaşlar üzerine hazırlanabilir. Çeșitli malzeme formları gibi ince film formunda hazırlanan bu malzemelerin elektriksel karakterizasyonları için özdirenç $(\rho)$ değerlerinin belirlenmesi çok önemlidir. 4-nokta tekniği, malzemelerin elektriksel özdirencini belirlemek için kullanılan oldukça yaygın bir tekniktir. Bu teknikte, aralarında belirli bir mesafe bulunan $(0.635-1.591 \mathrm{~mm}) 4$ yaylı kontak, bir eksen boyunca yüzeye temas eder. İki dış kontaktan uygulanan akım ve iki iç kontaktan okunan gerilim farkı ile yüzey direnci (sheet resistance) " $R_{s}$ " belirlenir. Bu teknikte akımın yönü değiştirilerek sadece iki ölçüm yapılabilir. Kullanılan bir diğer direnç-özdirenç ölçüm tekniği de Van der Pauw tekniğidir. Bu teknikle, örnek geometrisinden bağımsız olarak sekiz adet ölçüm yapılır ve $R_{s}$ belirlenir. Her iki ölçüm tekniğinin ortak donanımsal gereksinimi; örnek üzerine uygun değerde sabit akım uygulayabilecek bir akım kaynağı ve düşük gerilim değerlerini hassas şekilde ölçmek için yüksek empedanslı bir voltmetredir. Her ikisinde de malzeme kalınlı̆̆ bilgisi ile elektriksel özdirencin belirlenmesi mümkündür. Van der Pauw tekniğinin diğer avantajı ise manyetik alanın etkisinde ölçüm yapıldığında malzemedeki taşıyıcı türü, taşıyıcı konsantrasyonu, Hall katsayısı ve Hall mobilitesinin belirlenebilmesidir $\left[\begin{array}{ll}1, & 2\end{array}\right]$. Kapsamlı ve kolay uygulanabilir ölçüm teknikleri sayesinde, yariletken ince filmlerde biriktirme parametrelerinin ve katkılı-yarıiletkenlerde ise katkı türünün malzemenin karakteristik özelliklerine etkisi belirlenerek malzeme üretim aşaması yönlendirilebilir.

$\mathrm{Bu}$ çalışmada geliştirilen yeni ölçüm sistemi, uygun elektriksel kontak seçimi yapılarak uygulanan akıma karşı toplamda 16-farklı konfigürasyonda gerilim farkının ölçülmesine olanak vermektedir. Aynı zamanda çeşitli değişkenlere bağlı ölçümlerde, örneğin sıcaklık gibi her değişken değeri için elektriksel kontak çiftinin kısa sürede ve sürekli olarak değiştirilmesi gerekir. Bu nedenle kontaklar arası seçimin otomatik olarak yapılması, söz konusu fiziksel niceliklerin belirlenmesinde ortaya çıkabilecek kullanıcı hatalarını azaltacaktır.

Günümüz teknolojisinde uygun yazılım ve donanımlarla bilgisayar kontrolünde çeşitli hesaplama, grafik, görselleştirme, otomasyon vb. işlemler yapılmaktadır. Özellikle otomasyon ișlemlerinde maliyet ve kullanılan çevresel birimlerin fiziksel büyüklükleri de önem kazanmaktadır. Fakat mikro-kontrolcüler yardımı ile aynı ișlemler, daha uygun fiyat ve daha az hacim kaplayacak şekilde gerçekleștirilebilir. Son yıllarda çeşitli mikrokontrolcüler sayesinde farklı ve sayısı artan uygulamalar olduğu görülmektedir. Bunlar, fiziksel niceliklerdeki değişken $(\mathrm{pH}$, manyetik alan, renk, sıcaklık, basınç, kütle, nem vb.,) etkilerini izlemek için açık-kaynak kodları ile birlikte geliştirilmiş sensör modülleri ile kullanılmaktadır. Bunların aynı zamanda, internet bağlantısı, kablosuz bağlantı, USB bağlantıları ile diğer sistem veya aygitlar ile 
haberleșebilme yetenekleri de vardır. Hatta sadece veri girișine değil aynı zamanda çıkış portları ile (PWM, logic) oransal veya on-off kontrol sistemlerine dönüşebilmektedirler. Bunlara örnek olarak Microchip firmasına ait ATmega328 mikrokontrolcüsüne sahip Arduino UNO model mikrokontrolcü birimi verilebilir [3]. Arduino UNO, 6 adet PWM özelliği olan 14 dijital giriş/çıkış portu, 10-bit çözünürlüğe sahip 6 adet analog kanal girişi ve B-tipi Evrensel Seri Veri Yolu (Universal Serial Bus, USB) bağlantısına sahiptir. Arduino UNO temelde 10bit analog-sayısal dönüştürücüye sahiptir. Gerektiğinde daha yüksek çözünürlüklü (12-bit, 14-bit veya 16-bit) analog-sayısal dönüştürücü modüllerle birlikte kullanılabilir. $\mathrm{Bu}$ ve benzer özellikleri ile Arduino ailesinin farklı ürün platformları çok farklı işlevlerde kullanılabilir [4-6].

Bu çalışmada, Van der Pauw tekniği ile manyetik alanın olmadığı durumlarda ve manyetik alan etkisindeki yariiletken bir örnek yüzeyinde oluşturulan kontakların konfigürasyonunu otomatik olarak seçen, uygulanan akıma karşı gelen gerilim değerlerini ölçen ve bu sayede elektriksel niceliklerin belirlenmesini sağlayan bir sistem tasarlanmıștır. Bunun için iki adet Arduino UNO ve Arduino UNO uyumlu yardımcı kartlar kullanılmıștır. Ek olarak örnek malzemeye manyetik alan uygulayabilmek için $(<5000 G)$ iki Neodyum mıknatıs tașıyan, Arduino UNO ve iki adet adım motor sürücü birim ile kontrol edilebilen mekanik bir arabirim de tasarlanmıștır. Tasarlanan otomatik Hall/Direnç (OHD) ölçüm sistemi, elektriksel özellikleri bilinen farklı referans örnekler ile test edilmiş ve elde edilen sonuçlar bilinen değerler ile karșılaștırılmıș ve oldukça iyi bir uyum olduğu gözlenmiştir.

\section{Materyal ve Metod}

\subsection{Van der Pauw Tekniği ile Direnç ölçümü}

Van der Pauw tekniği ilk olarak 1958 yılında Leo J. Van der Pauw tarafından, ratgele biçime sahip malzemelerin özdirenç ve Hall etkisini ölçmek için kullanılmıştır $[7,8]$. Bu teknikte örnek malzeme, kalınlık ve yapısal olarak homojen kabul edilir. $\mathrm{Bu}$ durumda malzemenin köşelerinde örnek boyutuna kıyasla çok küçük boyutlarda oluşturulan 4 adet elektriksel kontaktan yararlanılarak yüzey direnci ve özdirenç belirlenebilir. Bu teknikte ardıșık iki kontak arasına akım uygulanırken, karșısındaki diğer iki kontak üzerinden gerilim farkı ölçülür. Literatürde kontakların isimlendirilmesi ile ilgili farklı notasyonlar vardır. $\mathrm{Bu}$ çalışmada kontaklar saat ibrelerinin tersi yönünde, sağ üst köşe "1" olacak şekilde ardışık olarak isimlendirilmiştir (Şekil 1-a). Ancak dikkat edilmesi gereken nokta; ölçülen gerilim değerlerinin pozitif olması gerekliliğidir. $\mathrm{Bu}$ ölçümler daha sonra akım yönü değiştirilerek tekrarlanır. Böylece 8 adet ölçüm yapılmış olur. Bütün kontak tellerinin malzeme türü ve geometrilerinin özdeş olması durumunda, kontaklardan kaynaklanan termoelektrik etki azaltılmış olur. Kontakların ohmik olması son derece önemlidir.

Tasarlanan ölçüm sisteminde elektriksel kontakların isimlendirilmesi, akım uygulaması ve gerilim ölçüm sırasına göre yapılmıștır. Sözgelimi $I_{21} V_{34} ; 2$. kontak $I_{+}, 1$. kontak $I$. ile 3. kontak $V_{+}$ve 4 . kontak $V$. simgeleriyle temsil edilmiștir. Buna göre 4 kontak için 8 farklı bağlantı konfigürasyonu ve hesaplanan dirençlerin arasındaki bağıntılar aşağıda verilmiştir;

$$
\begin{aligned}
& \mathrm{R}_{21,34}=\frac{V_{34}}{I_{21}}, \mathrm{R}_{12,43}=\frac{V_{43}}{I_{12}}, \\
& \mathrm{R}_{32,41}=\frac{V_{41}}{I_{32}}, \mathrm{R}_{23,14}=\frac{V_{14}}{I_{23}}, \\
& \mathrm{R}_{43,12}=\frac{V_{12}}{I_{43}}, \mathrm{R}_{34,21}=\frac{V_{21}}{I_{34}}, \\
& \mathrm{R}_{14,23}=\frac{V_{23}}{I_{14}}, \mathrm{R}_{41,32}=\frac{V_{32}}{I_{41}} .
\end{aligned}
$$

Elektriksel kontaklardaki akım yönü değiştirildiği zaman Eş. (2) ile ifade edilen dirençlerin

$$
\begin{aligned}
& R_{21,34}=R_{12,43} \\
& R_{32,41}=R_{23,14} \\
& R_{43,12}=R_{34,21} \\
& R_{14,23}=R_{41,32}
\end{aligned}
$$

birbirine eşit olması önemlidir. Ayrıca Şekil 1a'da verilen referans koordinat sistemine göre $y$ ekseni yönündeki direnç $R_{A}\left(\left(R_{21,34}+R_{12,43}+R\right.\right.$ $\left.43,12+R_{34,21}\right) / 4$ ) ve $x$-ekseni yönündeki direnç $R_{B}$ $\left(\left(R_{32,41}+R_{23,14}+R_{14,23}+R_{41,32}\right) / 4\right)$ ile $R_{s}$ arasinda Van der Pauw-NIST eşitliği olarak bilinen 


$$
\exp \left(\frac{-\pi R_{A}}{R_{S}}\right)+\exp \left(\frac{-\pi R_{B}}{R_{S}}\right)=1
$$

biçiminde bir ilişki vardır. Deneysel olarak ölçülen $R_{A}$ ve $R_{B}$ değerleri ile Amerikan Ulusal Standartlar ve Teknoloji Enstitüsü (National Institute of Standards and Technology, NIST) [9] tarafından verilen algoritmaya uygun şekilde iterasyon yapılarak Eş. (3)'ü sağlayan yüzey direnç $\left(R_{s}\right)$ değeri belirlenir. Daha sonra elektriksel özdirenç $\left(\rho=R_{s} / d\right)$ hesaplanır. Burada $d$ film malzemenin kalınlığıdır. Bu ișlemler sırasında geometrik faktör $\left(f\left(R_{A} / R_{B}\right)\right)$ " 1 " olarak dikkate alınmıştır. Buna göre Eș. (3)'ün yeniden düzenlenmesiyle özdirenç,

$$
\rho=\frac{\pi d}{\ln 2}\left(\frac{R_{A}+R_{B}}{2}\right) f\left(\frac{R_{A}}{R_{B}}\right)
$$

ile hesaplanabilir. Temel olarak Eş. (3) ve Eş. (4) bağıntılarının her ikisi de aralarında belirli bir mesafe bulunan 4-noktaya Gauss yasasının uygulanması sonucunda elde edilmektedir [10]. İdeal olmayan durumlarda geometrik faktör $(f)$ grafiksel ve/veya nümerik yaklaşımlarla belirlenmektedir. İdeal olmayan durumlarda $f$ değerinin değişiminin hesaplandığı örnek çalışmalar da vardır [11-16].

\subsection{Hall Tekniği ile Taşıyıcı Mobilitesi Ölçümü}

İlk olarak 1879 yılında Edwin H. Hall, manyetik alan altında akım taşıyan bir iletkenin akıma dik kenarlarında $\mu \mathrm{V}$ mertebesinde küçük bir gerilim farkı gözlemiştir [17]. Böylece tek bir ölçüm ile taşıyıcı türü, yüzey taşıyıcı konsantrasyonu ve film kalınlığının bilinmesi durumunda da taşıyıcının hacimsel konsantrasyonu hesaplanabilir. $\mathrm{Bu}$ niceliklerin $R_{S}$ ile birlikte değerlendirilmesiyle Hall katsayısı ve Hall mobilitesi hesaplanabilmektedir. Burada karşılaşılan en önemli sorun, ölçülen gerilim değerlerindeki ofset etkisidir. Bu ölçümler için (Şekil 1-b) pozitif ve negatif olarak değerlendirilen (örnek yüzeyinden dişa doğru ise $+z$ yönünde ve içe doğru ise $-z$ yönünde) $B$ manyetik alanı içindeki köşegen kontaklar kullanılarak iki set ölçüm yapılır. Hall ölçümleri için köşegen kontaklar, yapılan işleme uygun şekilde yeni bir konfigürasyonda isimlendirilmiştir. Buna göre ilk ölçümde $I_{13}$ ile 1 . kontak $I+$ ve 3 . kontak $I$-; $V_{24}$ için 2 . kontak $V+$ ve
4. kontak $V$. olarak dikkate alınmıştır. Sonraki adımda akımın yönü değiştirilerek ölçümler tekrarlanmıştır. Bu sayede simetrik olmayan kontaklardan veya örnek geometrisinden kaynaklanan ofset geriliminin etkisi azaltılmaktadır. $\mathrm{Bu} \quad 8$ adet ölçümle ilgili hesaplamalarda aşağıdaki isimlendirme kullanılmıştır:

$$
\begin{aligned}
& V_{C}=V_{24 \mathrm{P}}-\mathrm{V}_{24 \mathrm{~N}}, \\
& V_{D}=V_{42 \mathrm{P}}-\mathrm{V}_{42 \mathrm{~N}}, \\
& V_{E}=\mathrm{V}_{13 \mathrm{P}}-\mathrm{V}_{31 \mathrm{~N}}, \\
& V_{F}=\mathrm{V}_{31 \mathrm{P}}-\mathrm{V}_{13 \mathrm{~N}} .
\end{aligned}
$$

Hesaplamalarda malzemenin türünü belirlemek için toplam gerilim değeri $\left(V_{T}=V_{C}+V_{D}+V_{E}+V_{F}\right)$ dikkate alınır. Şayet $V_{T}$ negatif ise yariletken malzeme $n$-türü, pozitif ise malzeme $p$-türü özelliktedir. Yüzey taşıyıcı konsantrasyonu $\left(n_{s}\right)$ ve mobilite aşağıdaki Eș. (6) ve Eş. (7) yardımı ile hesaplanabilir:

$$
\begin{aligned}
& n_{s}=\frac{8 \times 10^{-8} I B}{q V_{T}} \\
& \mu=\frac{1}{q n_{s} R_{s}} .
\end{aligned}
$$

Buradaki $B$ (Gauss), $I$ (Amper), $n_{s}\left(\mathrm{~cm}^{-2}\right)$ ve $\mu$ $\left(\mathrm{cm}^{2} / \mathrm{Vs}\right)$ birimindedir. $q$ elektron yükü $1.602 \times 10^{-19}$ C'dur. Film kalınlığ $(d)$ dikkate alınarak hacimsel konsantrasyonu $n=n_{s} / d\left(\mathrm{~cm}^{-3}\right)$ ile hesaplanır.

\subsection{Otomatik Hall/Direnç Ölçüm Sistemi}

$\mathrm{Bu}$ çalışmada tasarımı gerçekleştirilen OHD ölçüm sistemi, temelde Van der Pauw tekniği ile direnç ölçüm sistemi ve Hall tekniği ile taşıyıcı mobilitesi ölçüm sisteminin bir arada kullanıldığı tümleşik bir sistemdir. Sistem ATmega328 mikrokontrolcüsüne sahip iki adet Arduino UNO, 16-kanal aktif "low" optik izolatörlü, tek-kontak röle kartı, iki adet adım motor sürücü birimden oluşmaktadır. Yariletken örnek yüzeyinde seçilen kontak çiftlerine sabit akım uygulayabilmek için GPIB bağlantısına sahip Keithley 2400 akım-gerilim kaynağı ve diğer kontak çifti arasındaki gerilim farkını ölçmek için ise Keithley 2000 model multimetre kullanılmıștır. 
Arduino ailesinin diğer üyeleri gibi UNO platformu da harici bir programlayıcıya ihtiyaç duymadan kendi önyüklemesi (bootloader) sayesinde kolayca programlanabilmektedir. Gerekli durumlarda Labview programı ile kullanmak mümkündür. Örnek tutucu yüzeyinde bulunan ve saat ibrelerinin tersi yönde numaralandırılan elektriksel kontakların (Şekil 1-a) röleler ile bağlantısı Şekil 1-b'de gösterilmiştir. Birinci Arduino UNO üzerinde bulunan ve çıkış olacak şekilde ayarlanan pinlerden alınan 8-bit kontrol sinyalleri (LSB olarak 9 numaralı pin ve MSB olarak 2 numaralı pin) ile uygun röleler aktif hale getirilerek ilgili kontaklara akım uygulanır (Şekil 1-c) ve bu kontak çiftinin karşısındaki diğer kontaklar arasındaki gerilim farkı multimetre ile ölçülür.

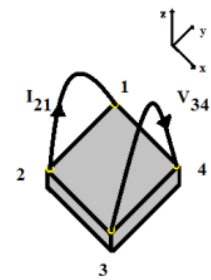

(a)

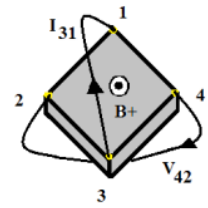

(b)
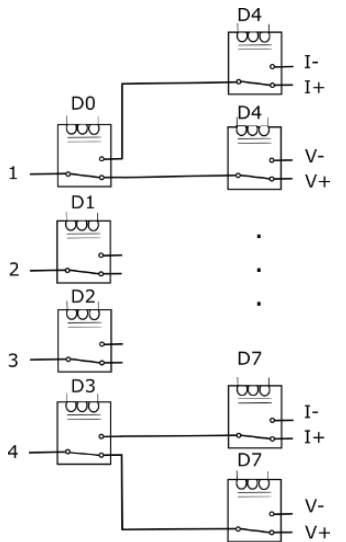

(c)

Şekil 1. Van der Pauw geometrisindeki elektriksel kontakların konfigürasyonu (a) direnç ölçümü için (b) mobilite ölçümü için ve

(c) kontakların temsili röle bağlantıları

Manyetik alan altında Hall ölçümleri için $5 \mathrm{~cm}$ çapında ve $3 \mathrm{~cm}$ uzunluğunda silindirik iki özdeș Neodyum mıknatıs, kanal genișliği $6,4 \mathrm{~cm}$ olan $U$ şeklindeki bir alüminyum blok içine stenilen derinlikte sabitlenmiş ve kutupları arasında uygun $(<5000 G)$ bir manyetik alan değeri sağlanmıştır. Bu sayede elde edilen manyetik alan şiddetini ölçmek için LakeShore 425 model Gaussmetre kullanılmıştır. İkinci Arduino UNO, 2 adet adım motor ve 2 adet adım motor sürücü ile mıknatısları taşıyan biri eksenel diğeri dairesel olarak hareket eden mekanik bir arabirim tasarlanmıştır. Tek-eksende ileri-geri hareket eden bu arabirim, manyetik alan kaynağını örnekten uzaklaştırmaktadır. Hareketli arabirim, ikinci eksende $180^{\circ}$ dönerek manyetik alanın, örnek yüzeyinden dışarı doğru (+B) ve örnek yüzeyinden içeri doğru olacak şekilde (-B) yönelimini sağlamaktadır. Her iki adım motorun yön ve adım kontrolünü sağlamak için Arduino UNO'da bulunan pinler (2, 3, 7 ve 8) kullanılmıştır (Şekil 2). OHD ölçüm sistemi Labview bilgisayar pragramı ile kontrol edilmektedir. Program iki ana bölümden oluşmaktadır. Programda ilk olarak yariletken örnek filme uygulanacak akım belirlenir. Daha sonra kullanıcı tarafindan Van der Pauw tekniği ile direnç ölçümü veya Hall ölçümü seçimi yapılır. Yapılan seçime göre 8-bitlik kodlar sırasıyla kontak seçici röle kartına gönderilir (Tablo 1). Akım kaynağının bağlı olduğu röleler aktiflenerek örnek filme belirlenen akım uygulanır. Direnç ölçümü için daha önceden belirlenen uygun kontaklar arasındaki gerilim değeri, 100 defa ölçülerek bir diziye aktarılır. Daha sonra bu dizinin ilk 20 ve son 20 elemanı dışında kalan 60 elemanın ortalaması alınarak kayıt altına alınır. Ölçümler tamamlandıktan sonra ortalama $R_{A}$ ve $R_{B}$ değerleri hesaplanarak, NIST tarafından verilen iterasyon algoritması vasitasiyla $R_{S}(\mathrm{ohm} / \mathrm{sq})$ yüzey direnci belirlenir. Örnek kalınlığı bilgisi ile özdirenç değerleri bulunur. İlk önce manuel olarak başlangıç konumunu ayarlamak amaciyla seçici anahtarlar kullanılarak manyetik alan kaynağı olan mıknatıs çifti konumlandırılır. Daha sonra Labview programı ile yazılan kontrol program, bu kez Hall ölçüm tekniği için çalıștırılır. Park konumundaki manyetik alan kaynağı Neodyum mıknatıslarla, örnek malzeme üzerine $+B$ yönünde manyetik alan uygulayacak şekilde seçim yapılır ve adım motor-I ile ölçüm noktasına hareket ettirilir. İki adet UNO kullanılarak mekanik sistem ile rölelerin bulunduğu birim, fiziksel olarak ayrılmış olur. Ancak birinci ve ikinci Arduino UNO birimler arasında $R_{x}$ ve $T_{x}$ pinleri ile haberleşme sağlanır. Böylece rölelerin kontaklarına Tablo 1'de verilen uygun kodlar gönderilerek ilk 4 ölçüm yapılır. 


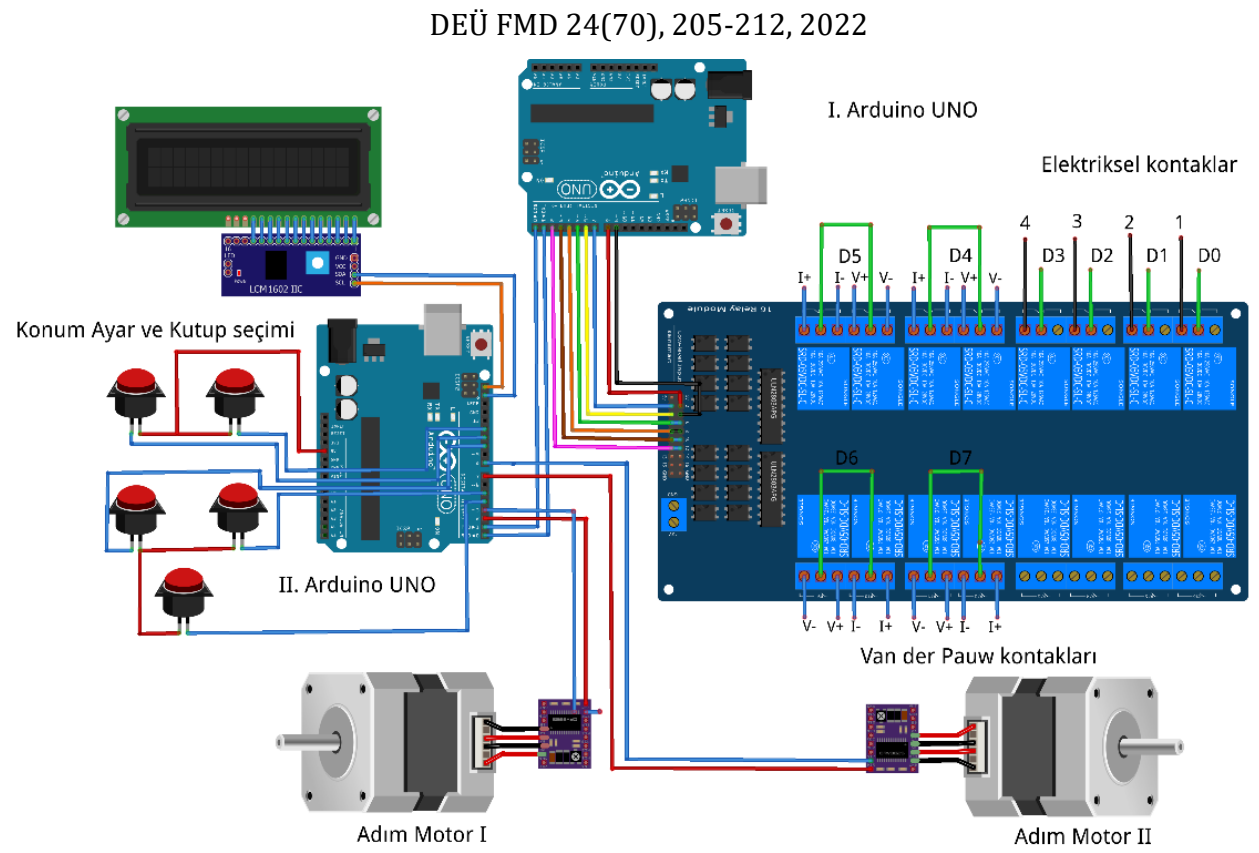

Şekil 2. Otomatik Hall/Direnç (OHD) ölçüm sisteminin temel bileșenleri

Tablo1. Van der Pauw ve Hall sistemlerindeki kontak grubu için 12 adet tek-kontak röle konfigürasyonları (0; Aktif, 1; Aktif değil)

\begin{tabular}{cclcccccccc}
\hline \multicolumn{1}{c}{ Van der Pauw Ölçümü için Röle Konfigürasyonu } \\
\hline Akım & Gerilim & Hex Data & $\mathbf{1 1 , 1 2}$ & $\mathbf{9 , 1 0}$ & $\mathbf{7 , ~}$ & $\mathbf{5 , 6}$ & $\mathbf{4}$ & $\mathbf{3}$ & $\mathbf{2}$ & $\mathbf{1}$ \\
\hline $\mathbf{1 2}$ & $\mathbf{4 3}$ & 0X9C & 1 & 0 & 0 & 1 & 1 & 1 & 0 & 0 \\
$\mathbf{2 1}$ & $\mathbf{3 4}$ & 0X6C & 0 & 1 & 1 & 0 & 1 & 1 & 0 & 0 \\
$\mathbf{2 3}$ & $\mathbf{1 4}$ & 0X39 & 0 & 0 & 1 & 1 & 1 & 0 & 0 & 1 \\
$\mathbf{3 2}$ & $\mathbf{4 1}$ & 0XC9 & 1 & 1 & 0 & 0 & 1 & 0 & 0 & 1 \\
$\mathbf{3 4}$ & $\mathbf{2 1}$ & 0X63 & 0 & 1 & 1 & 0 & 0 & 0 & 1 & 1 \\
$\mathbf{4 3}$ & $\mathbf{1 2}$ & 0X93 & 1 & 0 & 0 & 1 & 0 & 0 & 1 & 1 \\
$\mathbf{4 1}$ & $\mathbf{3 2}$ & 0XC6 & 1 & 1 & 0 & 0 & 0 & 1 & 1 & 0 \\
$\mathbf{1 4}$ & $\mathbf{2 3}$ & 0X36 & 0 & 0 & 1 & 1 & 0 & 1 & 1 & 0 \\
\hline
\end{tabular}

Hall Ölçümü için Röle Konfigürasyonu (+B ve -B için ayrı ayrı tekrarlanacak)

\begin{tabular}{cclcccccccc}
\hline Akım & Gerilim & Hex Data & $\mathbf{1 1 , 1 2}$ & $\mathbf{9 , 1 0}$ & $\mathbf{7 , 8}$ & $\mathbf{5 , 6}$ & $\mathbf{4}$ & $\mathbf{3}$ & $\mathbf{2}$ & $\mathbf{1}$ \\
\hline $\mathbf{1 3}$ & $\mathbf{2 4}$ & 0X3A & 0 & 0 & 1 & 1 & 1 & 0 & 1 & 0 \\
$\mathbf{3 1}$ & $\mathbf{4 2}$ & 0XCA & 1 & 1 & 0 & 0 & 1 & 0 & 1 & 0 \\
$\mathbf{4 2}$ & $\mathbf{1 3}$ & 0X95 & 1 & 0 & 0 & 1 & 0 & 1 & 0 & 1 \\
$\mathbf{2 4}$ & $\mathbf{3 1}$ & 0 0X45 & 0 & 1 & 0 & 0 & 0 & 1 & 0 & 1 \\
\hline
\end{tabular}




\section{DEÜ FMD 24(70), 205-212, 2022}

Bu işlemi takiben mıknatıslar park konumuna getirilerek adım motor-II yardımı ile $180^{\circ}$ döndürülür ve örnek malzeme üzerine $-B$ manyetik alanını sağlayacak şekilde yeniden konumlandırılır. Röle kontaklarına aynı kodlar sırasıyla gönderilerek geriye kalan 4 adet ölçüm yapılır. Bu sekiz adet ölçümden elde edilen gerilim değerleri, Eş. (5) yardımıyla değerlendirilir ve $V_{T}$ gerilim değeri hesaplanır. $V_{T}<0$ olması malzemenin $n$-türü, $V_{T}>0$ olması ise malzemenin $p$-türü olmasına işaret eder. $\mathrm{Bu}$ ölçüm sistemiyle, yüzeydeki taşıyıcı konsantrasyonu $\left(\mathrm{cm}^{-2}\right)$, örneğin kalınlık bilgisi kullanılarak elektriksel özdirenci, hacimsel taşıyıcı konsantrasyonu $\left(\mathrm{cm}^{-3}\right)$, Hall katsayısı ve taşıyıcı mobilitesi belirlenebilir.

\section{Bulgular}

Bu çalıșmada tasarlanan OHD ölçüm sistemi ilk olarak 1 ve 2 numaralı kontaklar arasına bağlanan $1 \mathrm{k} \Omega, 2$ ve 3 numaralı kontaklar arasına bağlanan $2.2 \mathrm{k} \Omega, 3$ ve 4 numaralı kontaklar arasına bağlanan $3.3 \mathrm{k} \Omega$ ile 4 ve 1 numaralı kontaklar arasına bağlanan $10 \mathrm{k} \Omega$ değerindeki dirençlerden oluşturulan direnç sistemi üzerinde test edilmiştir (Şekil 3).

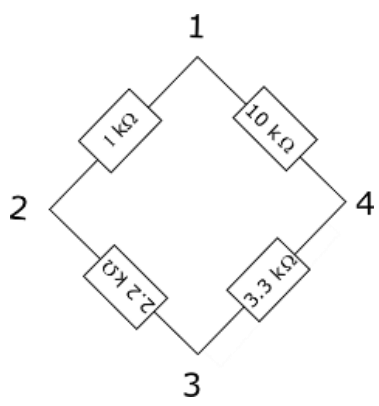

Şekil 3. Farklı değerlerdeki dirençlerden oluşan test örneği

$\mathrm{Bu}$ test örneğinin Van der Pauw konfigürasyonunda deneysel olarak elde edilen $R_{21,34}$ direnç değeri $200 \Omega$ ve $R_{24,13}$ direnç değeri ise $1315 \Omega$ olarak belirlenmiştir. Test örneğinin eşdeğer devre modeli kullanılarak [18] belirlenen teorik değerleri sırasıyla $R_{21,43}$ için $200 \Omega$ ve $R_{23,14}$ için $1330 \Omega$ olarak belirlenmiştir. Dirençlerin tolerans değerleri dikkate alındığında, deneysel ve teorik değerlerin uyum içinde olduğu gözlenmiştir. Örnekler üzerine uygulanacak olan uyarma akımının değeri önemlidir. Uygulanan akım değeri ve örnek direnci dikkate alındığında elektriksel güç $0.1 \mathrm{~W}$ değerinden büyük olmamalıdır. Daha sonra kroyostat içine yerleştirilen "1 numaralı" GaAs referans örnek için $100 \mu \mathrm{A}$ uyarma akımı kullanılarak vakum ortamında ölçümler yapılmıştır. Bu test örneklerinin iletkenlik türü, yüzey dirençleri, taşıyıcı konsantrasyonu ve mobiliteleri belirlenmiştir (Tablo 2). Kalınlık bilgisine sahip olduğumuz (10nm) n-tipi iletkenliğe sahip "1 numaralı" örneğin özdirenci $8.20 \times 10^{-4} \Omega \mathrm{cm}$ (referans değeri $8.19 \times 10^{-4} \Omega \mathrm{cm}$ ) olarak bulunmuștur. Ayrıca, n-tipi olduğu bilinen, üzerinde ohmik kontaklar bulunan AlGaN içerikli "2 numaralı" test örneği (uyarma akımı $10 \mu \mathrm{A}$ ) ile $p$-tipi ve üzerinde Indiyum kontaklar bulunan diğer GaN içerikli "3 numaralı" test örneği (uyarma akımı $1 \mu \mathrm{A}$ ) için yapılan ölçümler sonucunda hesaplanan parametreler Tablo 2'de verilmiştir. Deneysel ve teorik değerler arasında oldukça iyi bir uyum olduğu gözlenmiştir.

Tablo 2. OHD ölçüm sistemi kullanılarak bazı örnek malzemeler için yapılan ölçüm sonuçlarından belirlenen fiziksel nicelikler. $B$ manyetik alan $3800 \mathrm{G}$ olup, $R_{S}(\Omega / \square), n_{S}\left(1 / \mathrm{cm}^{2}\right)$ ve $\mu\left(\mathrm{cm}^{2} / \mathrm{Vs}\right)$ birimindedir.

\begin{tabular}{ccccc}
\hline Örnek & $\begin{array}{c}\text { İletkenlik } \\
\text { Türü }\end{array}$ & $\boldsymbol{R}_{\boldsymbol{s}}$ & $\boldsymbol{n}_{\boldsymbol{s}}$ & $\boldsymbol{\mu}$ \\
\hline 1 & $\mathrm{n}$ & 820 & $1.85 \times 10^{12}$ & 4124 \\
$1^{*}$ & $\mathrm{n}$ & 819 & $1.85 \times 10^{12}$ & 4120 \\
2 & $\mathrm{n}$ & 391 & $1.24 \times 10^{13}$ & 1290 \\
$2^{*}$ & $\mathrm{n}$ & 391 & $1.30 \times 10^{13}$ & 1286 \\
3 & $\mathrm{p}$ & 938 & $9.26 \times 10^{12}$ & 711 \\
$3^{*}$ & $\mathrm{p}$ & 933 & $9.20 \times 10^{12}$ & 727 \\
\hline
\end{tabular}

*Örneklere ait referans değerleri göstermektedir.

\section{Tartışma ve Sonuç}

Bu çalışmada Hall/Direnç ölçüm sistemi ve Van der Pauw konfigürasyonunda belirlenen elektriksel kontak dizilerini otomatik olarak yönlendiren Arduino UNO tabanlı bir tasarım gerçekleştirilmiştir. Ölçülen nicelikleri kullanarak yüzey direnci, taşıyıcı 


\section{DEÜ FMD 24(70), 205-212, 2022}

konsantrasyonu ve mobilite değerlerinin hesaplanmasında kullanılan bir bilgisayar programı sisteme entegre edilerek sistematik, hızlı ve güvenilir bir karakterizasyon sistemi elde edilmiștir. Motorize sistem ile örneklerin manyetik alan içindeki konumlarından kaynaklanabilecek kullanıcı hataları azaltılmıștır. Kararlı ve sabit akım uygulaması için hassas bir sabit akım kaynağı ve gerilimleri ölçmek için hassas bir voltmetre kullanılarak ölçüm hataları azaltılmıştır. Bu sayede sözdeörnek ve referans örnekler için yapılan ölçümler sonunda elde edilen fiziksel nicelikler ile bu örneklere ait referans alınan değerler arasındaki fark \%3'den küçük olarak hesaplanmıștır. Sonuç olarak bu çalıșmada hızlı, güvenilir, küçük hacmiyle kolay taşınabilir ve uygun maliyetli olan otomatik bir Hall/Direnç ölçüm sistemi tasarlanmıștır. $\mathrm{Bu}$ sistem, yariletkenlerin karakteristik elektriksel niceliklerinin sicaklık, ışık şiddeti ve/veya dalgaboyuna bağlı değişimlerinin incelenmesinde ve bunun yanısıra magnetodirenç ölçümleri gibi farklı karakterizasyonlarının yapılabilmesinde önemli bir potansiyele sahiptir.

\section{Teșekkür}

Bu çalıșma 116F046 nolu proje ile Türkiye Bilimsel ve Teknolojik Araștırma Kurumu tarafindan ve 110-NAP-10, 100-NAP-10, 173-NAP-13，0324-NAP-16，0356-NAP-16 ve 0253-MP-14 numaralı projeler ile Burdur Mehmet Akif Ersoy Üniversitesi Bilimsel Araştırma Projeleri Birimi tarafindan desteklenmiștir.

\section{Kaynakça}

[1] Beck, W.A., Anderson, J.R. 1987. Determination of electrical transport properties using a novel magnetic field-dependent Hall technique, Journal of Applied Physics, Vol. 62, p. 541-554. DOI:10.1063/1.339780.

[2] Wernera, F. 2017. Hall measurements on lowmobility thin films. Journal of Applied Physics, Vol. 122, (13), p. 135306-(1-13). DOI:10.1063/1.4990470

[3] Microchip.

https://www.microchip.com/wwwproducts/en/AT mega2560 (Erișim Tarihi: 06.12.2020).

[4] Ja'afaru, S., Dogara, M.D., Isaac, H.D., Gyuk, P.M., Iyen, C. 2018, Comparison Between a Constructed Arduino Based System and Keithley Sourcemeter 2400 on Some Electronics Devices, Science World Journal Vol. 13, No(2), p. 55-57. DOI:10.4314/SWJ.V13I2.

[5] Guvench, S., Denton, M., Rollins, M., Guvench, M. 2000, Automated Semiconductor Device/Sensor Measurement System For Temperature And
Magnetic Field Characterization, 2000 Annual Conference, 18-21.06.2000, St. Louis, Missouri, p. 5.119.1 - 5.119.8, DOI: 10.18260/1-2--8177.

[6] Güngör, T., Uslu, B., Güngör, E., Böbrek, A. 2019. Arduino Tabanlı Döndürerek İnce Film Kaplama Sistemi Tasarımı ve MgO İnce Film Üretimi, Uluslararası Mühendislik Tasarım ve Teknoloji Dergisi, Cilt 1. (1), s. 31-35.

[7] Van der Pauw, L.J., 1958. A method of measuring specifc resistivity and Hall efect of discs of arbitrary shape. Philips Research Reports, Vol. 13, p.1-9.

[8] Van der Pauw, L.J., 1958/1959. A. Method of measuring the resistivity and hall coefcient on lamellae of arbitrary shape. Philips Research Reports, Vol.20, p.220-224.

[9] NIST, https://www.nist.gov/pml/nanoscale-devicecharacterization-division/popular-links/hall-effect (Erișim Tarihi: 06.12.2020).

[10] El-Hinnawy, $\mathrm{N}$. https://www.microwaves101.com/encyclopedias/ van-der-pauw-measurements (Erișim Tarihi: 06.12.2020).

[11] Kasl, C., Kasl, M.J.R. 2005. Efects of sample thickness on the van der Pauw technique for resistivity measurements. Review of Scientific Instruments, Vol. 76, p033907-(1-4). DOI:10.1063/1.1866232.

[12] Smith, B.J., Chwang, R., Crowell, C.R. 1974. Contact size efects on the van der Pauw method for resistivity and Hall coefcient measurement. Solid-State Electronics, Vol. 17, p-1217-1227. DOI:10.1016/0038-1101(74)90001-X.

[13] Koon, D.W. 1989. Efect of contact size and placement, and of resistive inhomogeneities on van der Pauw measurements. Review of Scientific Instruments, Vol. 60, p 271-274. DOI:10.1063/1.1140422.

[14] Wu, B., Huang X., Han, Y., Gao, C., Peng, G., Liu, C., Wang, Y., Cul, X., Zou, G. 2010. Finite element analysis of the efect of electrodes placement on accurate resistivity measurement in a diamond anvil cell with van der Pauw technique. Journal of Applied Physics, Vol. 107, p-104903-(1-4). DOI:10.1063/1.3374466.

[15] Matsumura, T., Sato, Y.A. 2010. Theoretical study on van der Pauw measurement values of inhomogeneous compound semiconductor thin flms. Journal of Modern Physics, Vol. 1, p340347.DOI:10.4236/jmp.2010.15048.

[16] Reveil, M., Sorg, V.C, Cheng, E.R., Ezzyat, T., Clancy, P., Michael, O.T. 2017. Finite element and analytical solutions for van der Pauw and four-point probe correction factors when multiple non-ideal measurement conditions coexist. Review of Scientific Instruments, Vol. 88, p094704-(1-12). DOI:10.1063/1.5001830.

[17] Hall, E.H. 1879. On a New Action of the Magnet on Electrical Current. The American Journal of Mathematics, Vol. 2, p-287-292. DOI:10.2307/2369245.

[18] Ausserlechner, U. 2016. Closed form expressions for sheet resistance and mobility from Van-der-Pauw measurement on $90^{\circ}$ symmetric devices with four arbitrary contacts. Solid-State Electronics, Vol. 116, p-46-55. DOI: 10.1016/j.sse.2015.11.030. 